\title{
Dynamical Analysis Applied to Passive Control of Vibrations in a Structural Model Incorporating SMA-SE Coil Springs
}

\author{
Yuri J. O. Moraes $\left(\mathbb{D},{ }^{1}\right.$ Antonio A. Silva, ${ }^{2}$ Marcelo C. Rodrigues, ${ }^{1}$ Antonio G. B. de Lima (iD) ${ }^{2}$ \\ Rômulo P. B. dos Reis $\left(\mathbb{D},{ }^{3}\right.$ and Paulo C. S. da Silva ${ }^{2}$ \\ ${ }^{1}$ Department of Mechanical Engineering, Federal University of Paraiba, SN/58.051-085 João Pessoa, PB, Brazil \\ ${ }^{2}$ Department of Mechanical Engineering, Federal University of Campina Grande, Avenue Aprígio Veloso, \\ 882/58.429-900 Campina Grande, PB, Brazil \\ ${ }^{3}$ Department of Technology and Engineering, Federal University Rural of Semi-Árido, Avenue Francisco Mota, Costa e Silva, \\ 572/59.625-900 Mossoró, RN, Brazil
}

Correspondence should be addressed to Yuri J. O. Moraes; yurijmoraes@gmail.com

Received 23 March 2018; Revised 1 June 2018; Accepted 6 June 2018; Published 10 July 2018

Academic Editor: Wen Deng

Copyright (@) 2018 Yuri J. O. Moraes et al. This is an open access article distributed under the Creative Commons Attribution License, which permits unrestricted use, distribution, and reproduction in any medium, provided the original work is properly cited.

\begin{abstract}
Mechanical vibrations are severe phenomena of the physical world. These oscillations may become undesirable and may cause temporary and even irreversible damage to the system. There are several techniques to minimizing these vibration effects ranging from passive methods to the use of controllers with smart materials. In this sense, this study aims to analyze a passive vibration control system installed in a structure that simulates two-floor buildings. This system based on the incorporation of one SMA-SE (Superelastic Shape Memory Alloys) coil springs configuration for energy dissipation and the addition of damping. Modal analysis was performed using analytical, numerical, and experimental methods. In an experimental basis, response amplitudes were analyzed for free and forced vibrations in different configurations. As compared with the structure configuration with steel spring, the forced vibrations FRF (Frequency Response Function) analysis showed a reduction in displacement transmissibility of up to $51 \%$ for the first modal shape and $73 \%$ for the second mode in the SMA-SE coil spring configuration. As for damping, there was a considerable increase in the order of $59 \%$ in the first mode and $119 \%$ in the second, for the SMA-SE springs configuration.
\end{abstract}

\section{Introduction}

A periodic oscillation or mechanical vibration is a phenomenon defined as any movement that comes repeated after some time. Thus, the theory of vibration studies the oscillatory movements of the bodies and the forces associated with them. In general, a vibratory system alternates the transfer of its potential energy to kinetic energy. This system generally contains a means for storing potential energy, for example, a spring, another for storing kinetic energy, as a mass, and finally, one for gradually dissipating energy, called as damper $[1,2]$.

Under the viewpoints of mechanics, can be verified these effects easily in our everyday life, whether in the use of domestic appliances or the mining industry, among other forms [3]. However, some physical phenomenon may become undesirable and may cause temporary or irreversible damage in a specific system, due to the malfunction, the progressive increase of noise, shortened life of its components, increased maintenance costs, and in the more severe cases with the own collapse or structural failure. Thus, in the case of an architectural project, taking into account not only the load exerted by the weight of the system is crucial. Also, the loads are derived from the conditions of the own use, such as the movement of people, automobiles, loads, among others. However, it is of equal importance to consider the effects provoked by natural phenomena, like winds, and waves of the sea [4-6].

Another type of excitation in structures is earthquakes, usually associated with a kind of action imposed by a base 


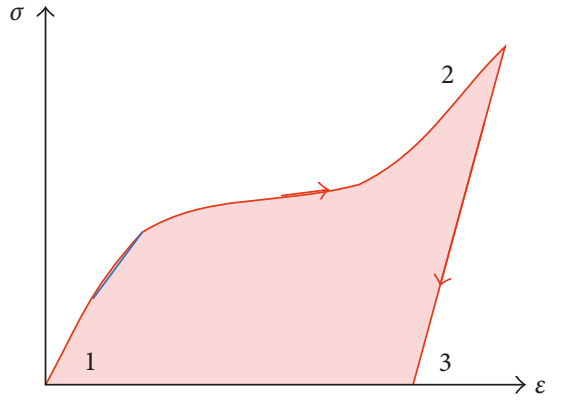

(a)

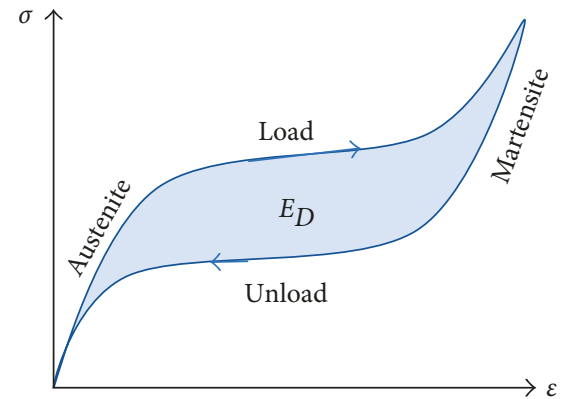

(b)

FIgUre 1: Representation of the two effects of an SMA. (a) SME and (b) SMA-SE.

excitation. Earthquake is related to the movements of the surface layers of the Earth, causing a deformation in the broad masses of rocks, which when broken, generate traveling waves in the Earth, provoking the earthquake $[7,8]$. The seismic action depends on the mass of the structure, damping, and stiffness of its components. The behavior of a structure under earthquake conditions is a dynamic problem because the seismic movement causes forced vibration in it. Thus, several studies focus on the amplitudes and duration times of the vibration [9-11].

As a result, it is observed that many countries in Europe and Asia suffered the effects of natural disasters, with earthquakes contributing to more significant damage $[12,13]$. In Brazil, the risks of a natural cause's shock are of remote chances, since there are no geological faults with sufficient dimensions to generate such an effect; however, specific human activities can also cause earthquakes, the socalled induced earthquakes. These vibrations are due to the construction of significant works, the actions of massive explosions, and the traffic of vehicles, which are associated with the human activity. The collapses and structural failures related to these earthquakes can arise because of the physical phenomenon well known as resonance, defined as the propensity of a system to oscillate at maximum amplitude under specific natural frequencies of the system. At these frequencies, even small forces can produce large-amplitude vibrations because the system stores sizeable vibration energy [14].

Techniques and models have been used to minimize the implications of these vibrations. The first studies with passive viscoelastic absorbers with a structural damping function date back to the 1950s [15-18]. In structural engineering, one of the first applications is related to the design of viscoelastic dampers used in the former WTC (World Trade Center) building, located in New York, USA [19], where 10,000 dissipators were used in each of the towers with the specific function of absorbing vibrations originated from dynamic actions of wind.

Currently, the materials most used for the needs imposed by the structural systems are the type with SME (Shape Memory Effect), where the main ones are the metallic alloys and polymers. In the metallic materials, the SME characteristic is the reaction to change in temperature, so-called SMA, and in some cases, to change under mechanical stress known SMA-SE. These reactions are solid-state martensitic transformations [20-22]. Figure 1 shows a typical curve of these two-distinct phenomena. In Figure 1(a) is presented the SMA thermally active, in which the segments 1 and 2 establish that the material is submitted to an external load and modify its shape in the martensitic phase. After removing this external load, one small recovery segment occurred (2-3). To complete recovery, a change in temperature is necessary to transform the martensitic phase in the austenite phase. In the other hand, in SMA-SE the external load (Figure 1(b)) provokes a full-phase transformation from the austenite to the martensitic phase. Upon unloading, a reverse phase transformation is achieved. A complete load-unload cycle gives as result a hysteresis curve. The difference between the curves represents the dissipated mechanical energy.

In this way, the SMA used as an active actuator (requires an external source of energy) is inefficient because it is thermoactive: this means it has a low-frequency response up to $10 \mathrm{~Hz}$. Further, the SMA-SE active per stress field can act as passive damping (without the need of external power source) capable of operating from low frequencies to frequencies above $10 \mathrm{~Hz}$. In fact, the SMA-SE responds as fast as the change in strain submitted to stress field [23].

The use of these materials has greatly increased in the last decades, where many researchers have intensively carried out activities that aim to explore devices and applications that make use of them. In fact, the number of commercial applications is growing each year, with the largest market segment represented by actuators and motors. The global smart materials market in 2010 was approximately $\$ 19.6$ billion, estimated at $\$ 22$ billion in 2011, and more than $\$ 40$ billion by 2016 , with an annual growth rate of $12.8 \%$ between 2011 and 2016 [24-26].

A selection of SMA is available in the market, but only a few have developed on a commercial scale. From the discovery of Nitinol in 1963, many SMA's were investigated and adapted to specific requirements, such as modulus of elasticity and electrical resistivity, as for the use of sensors and actuators, for example. Nowadays, over $90 \%$ of all applications are based on NiTi, NiTiCu alloys, or NiTiNb alloys [27-30].

Then, based on the information related to SMA, this study aimed to perform a comparative analysis between the 


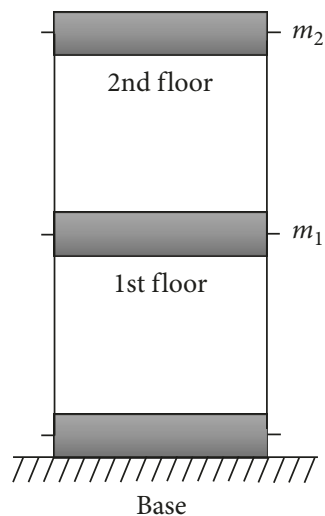

(a)

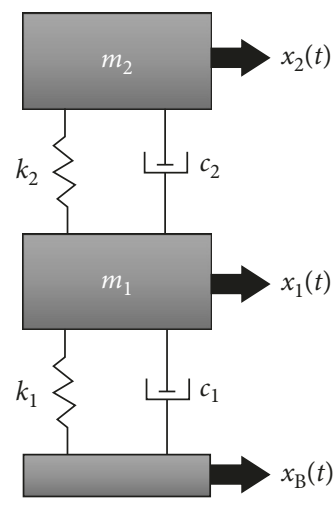

(b)

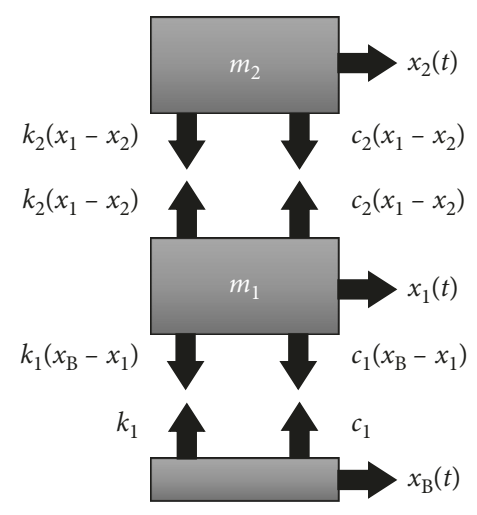

(c)

Figure 2: Representation of a 2DOF system with base excitation. (a) A simple model that simulates a two-floor building, (b) diagram of concentrated masses, and (c) free-body diagram of the structure.

use of elastic structural elements (steel springs) and elements of Nitinol alloy (SMA-SE springs) for the passive control of vibrations in structural systems. While the steel springs modify the structural parameters of stiffness and mass without incorporating any damping in the system and do not decrease the response amplitudes, the smart material increases the damping with only a small variation of these parameters and reduces the amplitudes in significant percentages, showing its superior efficiency and reliability.

This direct comparison is the main contribution of the research about previous works, showing the high possibility of the use of SMA-SE in dynamic systems with the aim of mitigates mechanical vibrations.

\section{Methodology}

This section describes a structural model that simulates twofloor buildings. The mathematical formulation is applied in an underdamped system with 2DOF (Two Degrees of Freedom) excited by the base. Thus, a numerical modal analysis of the system was performed without the SMA-SE absorbers, followed by the experimental stage, as a way of studying the structure with the elements of dissipation. Finally, a static characterization of the SMA-SE coil springs was performed.

2.1. Analytical Procedure. A free-body diagram illustrating the spring forces acting on each mass (Figure 2(a)) is illustrated in the Figures 2(b) and 2(c). The system will be analyzed when subjected to a forced excitation acting in the base. The constants $\mathrm{cl}$ and $\mathrm{c} 2$ indicate the structural damping imposed on the system. More details can found in the literature [31].

Summing the forces applied in each mass (in the horizontal direction) and applying Newton's law of equilibrium to the system yields (1).

$$
\begin{array}{r}
m_{1} \cdot \ddot{x}_{1}-c_{1}\left(\dot{x}_{B}-\dot{x}_{1}\right)+c_{2}\left(\dot{x}_{1}-\dot{x}_{2}\right) \\
-k_{1}\left(x_{B}-x_{1}\right)+k_{2}\left(x_{1}-x_{2}\right)=0, \\
m_{2} \cdot \ddot{x}_{2}-c_{2}\left(\dot{x}_{1}-\dot{x}_{2}\right)-k_{2}\left(x_{1}-x_{2}\right)=0 .
\end{array}
$$

After a rearrangement of terms of (1) and (2), (3) is obtained. In this equation, " $f_{1}(t)$ " is the input harmonic force imposed on basis of the structure, which is a function of the stiffness and damping of the first floor. The displacement, velocity, and " $f_{2}(t)$ " are null.

$$
\begin{aligned}
& {\left[m_{1} \cdot \ddot{x}_{1}+\left(c_{1}+c_{2}\right) \cdot \dot{x}_{1}+\left(k_{1}+k_{2}\right) \cdot x_{1}\right]} \\
& \quad+\left[-c_{2} \cdot \dot{x}_{2}-k_{2} x_{2}\right]=\left[k_{1} \cdot x_{B}+c_{1} \cdot \dot{x}_{B}\right]=f_{1}(t), \\
& {\left[m_{2} \cdot \ddot{x}_{2}+c_{2} \cdot \dot{x}_{2}+k_{2} \cdot x_{2}\right]} \\
& \quad+\left[-c_{2} \cdot \dot{x}_{1}-k_{2} \cdot x_{1}\right]=0=f_{2}(t) .
\end{aligned}
$$

Modifying (3) into the domain of Laplace transforms, we assume that the initial conditions of the system are zero and that " $F_{1}(s)=\left\{k_{1} \cdot\left[X_{B}(s)\right]+c_{1} \cdot\left[s \cdot X_{B}(s)-x_{B}(0)\right]\right\}$." Now, taking the displacement values in evidence, that is, “ $[A] \cdot[X(s)]=[F(s)]$," we can write

$$
\begin{aligned}
& {\left[\begin{array}{cc}
s^{2} \cdot m_{1}+s \cdot\left(c_{1}+c_{2}\right)+\left(k_{1}+k_{2}\right) & -s \cdot c_{2}-k_{2} \\
-s \cdot c_{2}-k_{2} & s^{2} \cdot m_{2}+s \cdot c_{2}+k_{2}
\end{array}\right]} \\
& \cdot\left[\begin{array}{l}
X_{1}(s) \\
X_{2}(s)
\end{array}\right]=\left[\begin{array}{c}
F_{1}(s) \\
0
\end{array}\right] .
\end{aligned}
$$

For (4), four transfer functions were obtained in the Laplace domain " $\left[X_{1}(s) / F_{1}(s), X_{1}(s) / F_{2}(s), X_{2}(s) / F_{1}(s)\right.$ and $X_{2}(s) / F_{2}(s)$ ]." For this case, $F_{2}(s)$ is always 0 since there is no other force acting in the system, other than the base excitation. Using Cramer's rule, one can solve the matrix equation for the displacements. The results are 


$$
\begin{aligned}
X_{1}(s)= & {\left[\frac{s^{2} \cdot m_{2}+s \cdot c_{2}+k_{2}}{\operatorname{det}(A)}\right] \cdot F_{1}(s)+\left[\frac{-s \cdot c_{2}-k_{2}}{\operatorname{det}(A)}\right] \cdot F_{2}(s), } \\
X_{2}(s)= & {\left[\frac{-s \cdot c_{2}-k_{2}}{\operatorname{det}(A)}\right] \cdot F_{1}(s) } \\
& +\left[\frac{s^{2} \cdot m_{1}+s \cdot\left(c_{1}+c_{2}\right)+\left(k_{1}+k_{2}\right)}{\operatorname{det}(A)}\right] \cdot F_{2}(s),
\end{aligned}
$$

in which the "det $(A)$ " is given as follows:

$$
\begin{aligned}
\operatorname{det}(A)= & {\left[s^{2} \cdot m_{1}+s \cdot\left(c_{1}+c_{2}\right)+\left(k_{1}+k_{2}\right)\right] } \\
& \cdot\left[s^{2} \cdot m_{2}+s \cdot c_{2}+k_{2}\right]-\left(-s \cdot c_{2}-k_{2}\right)^{2} .
\end{aligned}
$$

Since that, " $F_{2}(s)=0$," we have only two transfer functions that govern our system " $\left[X_{1}(s) / F_{1}(s) \mathrm{e} X_{2}(s) / F_{1}(s)\right]$." So, by multiplying these equations by the modal rigidities " $k_{1}$ " and " $k_{2}$ " respectively, we obtain the measured responses in the masses " $m_{1}$ " and " $m_{2}$ " simultaneously, as follows:

$$
\begin{aligned}
& H_{11}(s)=\frac{X_{1}(s) \cdot k_{1}}{F_{1}(s)}=\left[\frac{s^{2} \cdot m_{2} \cdot k_{1}+s \cdot c_{2} \cdot k_{1}+k_{2} \cdot k_{1}}{\operatorname{det}(A)}\right], \\
& H_{21}(s)=\frac{X_{2}(s) \cdot k_{2}}{F_{1}(s)}=\left[\frac{-s \cdot c_{2} \cdot k_{2}-k_{2} \cdot k_{2}}{\operatorname{det}(A)}\right] .
\end{aligned}
$$

We admit that a system with two independent coordinates subjected to a primary harmonic excitation can be defined by two transfer functions by using the Laplace Transform method, as in (7) and (8).

To obtain the analytical response in the frequency domain, a simulation code in the Matlab ${ }^{\circledR}$ software was developed and can be seen in the literature [31].

2.2. Numerical Procedure. For the numerical analysis of the system was developed a virtual structural model. With this model were determined the natural frequencies of the system with their respective modal shapes. In this analysis, the maximum and minimum displacements of amplitudes at each point of the structure can be visualized. For the development of the model, the design and modeling commercial software AutodeskInventor ${ }^{\circledR}$ version 2015 was used. For the modal analysis, was used the software Ansys ${ }^{\circledR}$ version 15.0 applying the FEM (Finite Elements Method).

The structural design in a computational environment was carried out with the objective of determining the geometric dimensions of the system. The idea is verifying the structural stability of the system via modal analysis.

The simulation is an essential stage of design since it has as objective to verify the dynamic behavior of the system, preventing failure in this process, which can compromise the physical integrity of the structure in operation.

In this process, the model was defined from the selection of the materials for each element that constitutes the structure, finishing with the choice of the control block for modal analysis. A mixed mesh with a predominance of hexahedral elements, containing 31,074 nodes and approximately 4,047 elements, was used, along with the selection of the "Base" floor as a fixed component of the system. In Figure 3 is illustrated the mesh generated before the simulation with the use of FEM.

\subsection{Experimental Procedure}

2.3.1. Structural Model and Absorber Elements. In this study, a structural model was designed and built in the LVI ( $\mathrm{Vi}$ bration and Instrumentation Laboratory) of the UFCG (Federal University of Campina Grande, Brazil). The prototype model consists of carbon steel beam for the composition of floors, rectangular stainless steel plates (AISI 304) for column composition, and as connecting elements Allen bolts of steel. Table 1 and Figure 4 summarize the number of elements, physical parameters, and dimensions of the prototype used in the fabrication of the structure.

Two structural configurations were used. The first one uses elastic elements of the type steel coil springs and the second with coil springs of superelastic effect (SMA-SE NiTi) at room temperature. In the second case, damping in the structure was due to the thermomechanical property of pseudoelasticity present in SMA-SE.

The SMA-SE coil springs were mechanically characterized by Instron 5582 at room temperature, using quasistatic load, with displacement control at $3 \mathrm{~mm} / \mathrm{min}$ up to $445 \%$ strain. The thermal characterization was done by DSC (Differential Scanning Calorimeter) with $5^{\circ} \mathrm{C} / \mathrm{min}$ from $100^{\circ} \mathrm{C}$ to $-60^{\circ} \mathrm{C}$, in order to verify the temperatures of the phase transformation.

The SMA-SE coil springs initially have orthodontic function and are commercialized by the Dental Morelli Company. Figure 5 shows the springs used in the study. In their original state, the SMA-SE coil springs are commercialized with different lengths between the eyelets (7.0, 9.0, 12.0 , and $15.0 \mathrm{~mm}$ ). However, the lengths " $\mathrm{M} 7=7.0 \mathrm{~mm}$ " and "M12 $=12.0 \mathrm{~mm}$ " were selected due to better adaptation to the displacement amplitudes of the structure in the second and first floor, respectively. Thus, it is possible to obtain a higher efficiency of energy dissipation.

For other types and configurations of the elements incorporated, the useful length and the length between eyelets ( $L_{\mathrm{u}}$ : useful length, $L_{\mathrm{o}}$ : length between eyelets, $N_{\mathrm{e}}$ : number of active turns, and $V_{\mathrm{m}}$ : volume of the useful material) were checked. These values are reported in Table 2.

For SMA-SE spring (M7), the number of active turns is seven, while in SMA-SE spring (M12), that number is twenty-six. Both have an initial turn angle equal to zero, initially closed. For the calculation of the linear deformation of the springs, the useful length of $2.5 \mathrm{~mm}$ was considered for M7 and $7.5 \mathrm{~mm}$ for M12 according to the point of crimping of the eyelets.

As for system tests incorporating SMA-SE elements, a spring type was attached for each floor, and calculated the total volume of useful material incorporated into the 


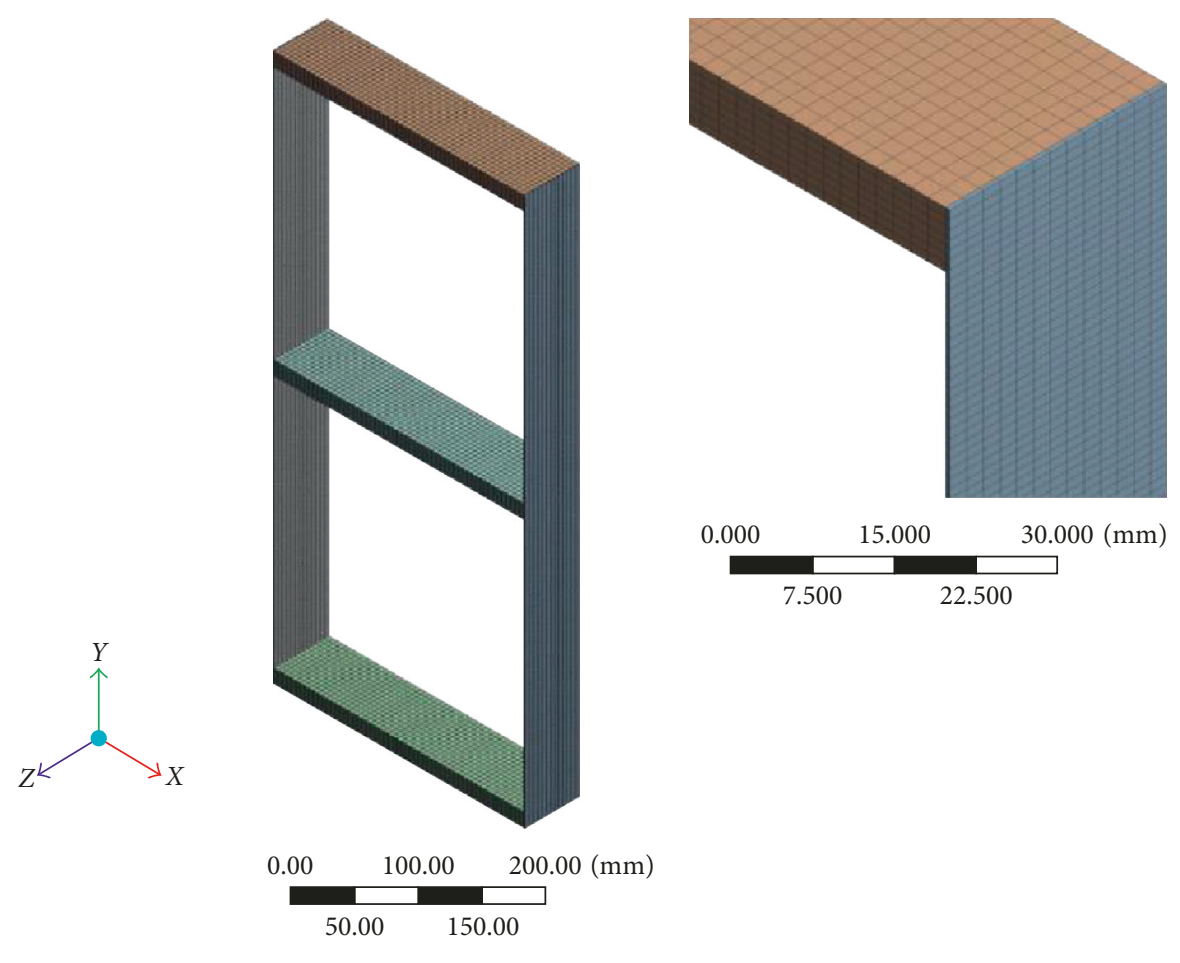

(a)

(b)

Figure 3: (a) The mesh of the physical model and (b) detail of the mesh in the columns.

TABle 1: Description of the components used in the structural construction.

\begin{tabular}{lcccc}
\hline Description & Dimensions $(\mathrm{mm})$ & $E(\mathrm{GPa})$ & Mass $(\mathrm{kg})$ & 1.110 \\
\hline Steel beam 1020 & $228.0 \times 50 \times 12.80$ & 200 & 0.190 & 3 \\
Stainless plate 304 & $501.6 \times 50 \times 0.97$ & 193 & 0.004 & 2 \\
Allen bolt $\left(3 / 4^{\prime \prime}\right)$ & $9.5 \times 15.50$ & 200 & 3.806 & 24 \\
Total & - & - & Amount & 29 \\
\hline
\end{tabular}

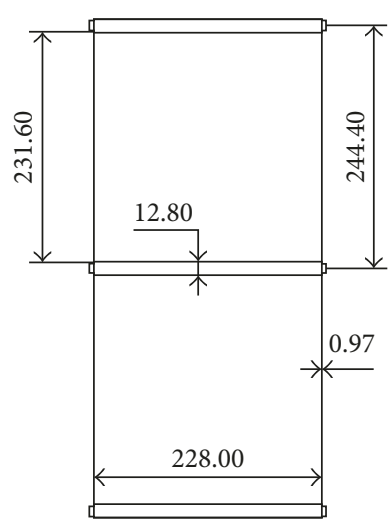

(a)

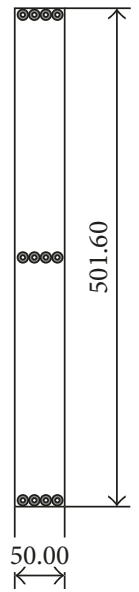

(b)

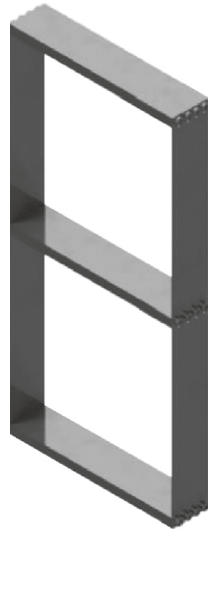

(c)

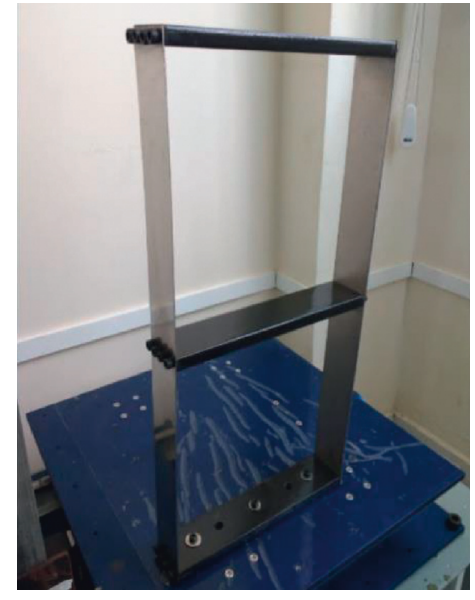

(d)

FIgure 4: Technical drawing of the prototype. (a) Front view, (b) lateral view, (c) exploded view of the structure, and (d) real model on the shake table. 


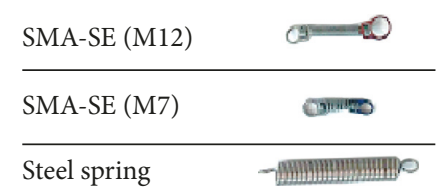

(a)

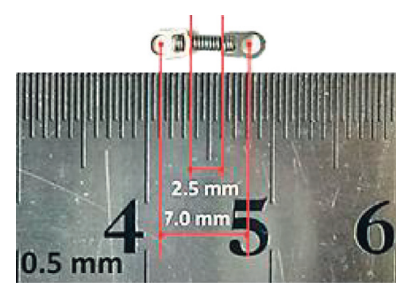

(b)

FIGURE 5: Absorber elements. (a) Springs used in the study and (b) length between eyelets and useful of the SMA-SE coil spring (M7).

TABLE 2: Dimensional parameters of the absorber elements.

\begin{tabular}{lcccc}
\hline Absorber elements & $L_{\mathrm{u}}(\mathrm{mm})$ & $L_{\mathrm{o}}(\mathrm{mm})$ & $N_{\mathrm{e}}(\mathrm{unnit})$ & 47 \\
Steel spring & 15.0 & 21.0 & $V_{\mathrm{m}}\left(\mathrm{mm}^{3}\right)$ \\
SMA-SE coil spring (M7) & 2.5 & 7.0 & 7 & 41.470 \\
SMA-SE coil spring (M12) & 7.5 & 12.0 & 26 & 2.494 \\
\hline
\end{tabular}

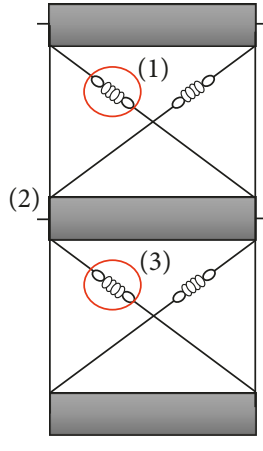

(a)

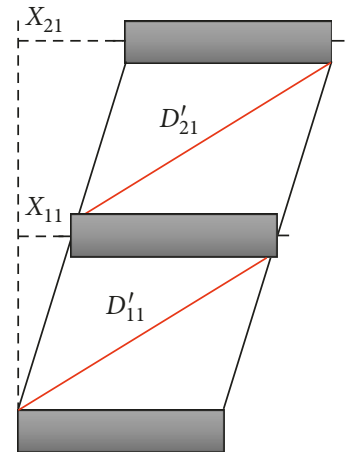

(b)

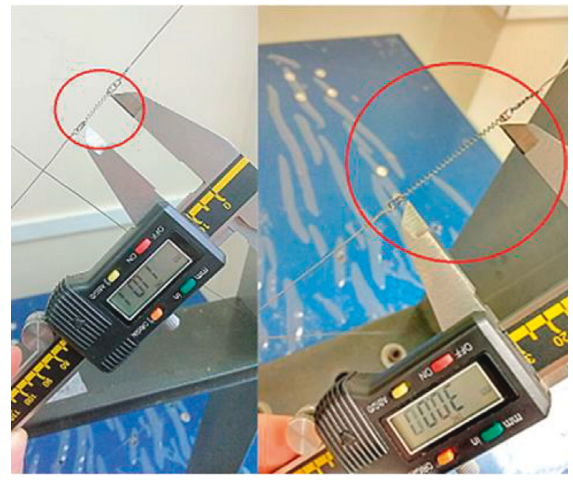

(c)

FIgURE 6: Coupling of the springs in the structure. (a) Illustrative representation of the arrangement of the elements, (b) procedure for measuring the deformation of the SMA-SE coil springs, and (c) calibration procedure for the springs.

structure. For the system configuration with SMA-SE springs, the entire material volume was about $88 \%$ less than in the case of steel springs, thus verifying that on a real scale, an optimization due to reduction in the material and space of the absorbers will be obtained.

The steel wires were received with an initial pretensioning to deform the SMA-SE springs at a certain level, allowing them to be in the superelastic region before performing dynamic tests. Following this recommendation was obtained this offset through measurements realized with an instrument used to measure displacements.

Assuming the springs have a much lower stiffness than steel wires, we can consider that the increase in damping imposed on the system must be associated with absorbers SMA-SE only. Figure 6(a) shows the connection of the steel wires in the system (1) and (3), which is fixed by anchor bolts (2). One can also observe the calibration procedure for the offset of the springs in Figure 6(c).

In this setup, when requesting the structure, it will move by expanding the vibration absorber element, occurring to the direct/martensitic phase transformation of the SMA-SE, and achieve the reverse/austenitic transformation when discharging the element, passing through the central point and forming the hysteretic energy dissipation loop.

To obtain the initial deformation, the forced vibration test of the model without the presence of absorbers was carried out, to determine the maximum deflection in each floor of the structure and the deformation in each diagonal.

Figure 6(b) shows the scheme for determining the parameters " $D_{11}^{\prime}$ " and " $D_{21}^{\prime}$ " of the first and second floor when it is subjected to the excitation relating to the first modal shape. After analysis of the FRF experimental curves, the displacement values " $X_{1 i}$ " and " $X_{2 i}$ " can be obtained for the maximum deflection at each floor, with " $i=1,2$ " corresponding to the first and second modal shapes. These values can be obtained using (9) and (10):

$$
\begin{aligned}
& X_{1 i}=T_{d 1 i} \cdot A_{1 i}, \\
& X_{2 i}=T_{d 2 i} \cdot A_{2 i},
\end{aligned}
$$

where " $T_{d 1 i}$ " and " $T_{d 2 i}$ " represent the transmissibility of displacement with respect to the base and analogously " $A_{1 i}$ " and " $A_{2 i}$ " the input amplitude at the base for the excitation function. Assuming that " $X_{1 i}$ " has the same value for the 


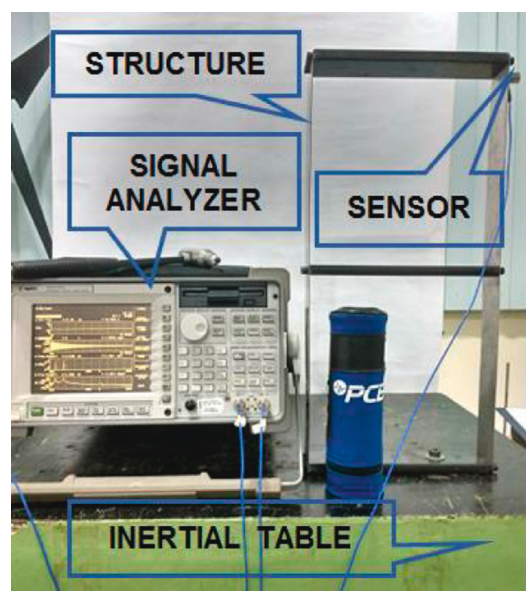

(a)

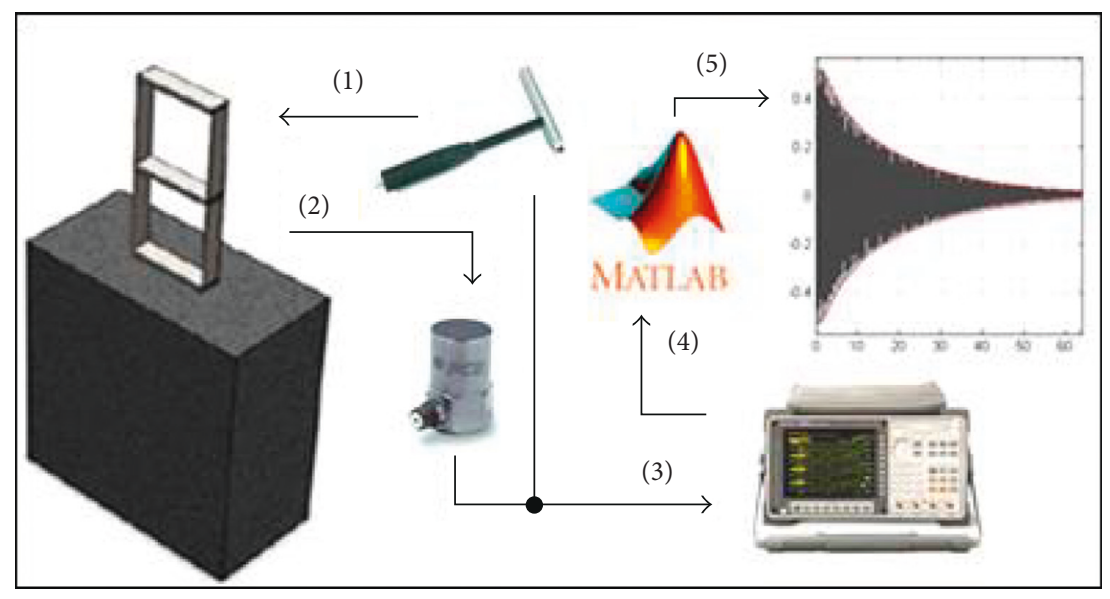

(b)

FIGURE 7: (a) Experimental setup of the structure tests in free vibration and (b) schematic representation of the experimental procedure in the free vibration tests.

entire thickness of the bar, the values of deformation in each diagonal are obtained in the condition of the first modal shape, using (11) and (12) as follows:

$$
\begin{aligned}
& D_{11}^{\prime}=\sqrt{\left(l_{1}\right)^{2}+\left(X_{11}+P_{1}\right)^{2},} \\
& D_{21}^{\prime}=\sqrt{\left(l_{2}\right)^{2}+\left[\left(X_{21}-X_{11}\right)+P_{2}\right]^{2},}
\end{aligned}
$$

where, from the data of the technical drawing of the structure (Figure 4), $l_{1}=l_{2}=231.60 \mathrm{~mm}$ and $P_{1}=P_{2}=228.00 \mathrm{~mm}$. Analogously, the values of these same parameters related to the second modal shape of the system can be found using (11) and (12), using $(i=2)$. In this way, the strategy of using a minimum initial elongation must be adopted, ensuring that the maximum deformation does not exceed the elastic or final regime of the hysteresis loop.

2.3.2. Free Vibration Setup. For the experimental tests in free vibration, was fixed the structure on the inertial table supported by vibra stops. The inertial table has a natural frequency lower than the primary frequencies of the system tested.

This experiment aims to determine the time response graph in which the amplitudes, regarding acceleration, and the period of vibration attenuation in the system are determined. The frequency spectrum was obtained in the cases where it is possible to visualize the natural frequency peaks and values of the structure to validate the analytical results. Figure 7(a) shows the actual assembly and the instrumentation used.

The setup of instrumentation is composed by an impact hammer $\left(P C B^{\circledR}\right.$ 086D05) which was used to generate a transient input signal and an accelerometer type sensor ( $P C B$ 353B01) to pick up the output signal. The data were collected by the signal analyzer, the (Agilent ${ }^{\circledR}$ Model 37670 A). Following, they were manipulated in the Matlab software.

The tests were divided in three stages: no absorbers elements, with the steel springs, and with the SMA-SE coil
TABLE 3: Characteristics of the Shake Table II Quanser.

\begin{tabular}{lc}
\hline Dimensions & $61.0 \times 46.0 \times 13.0 \mathrm{~cm}$ \\
Maximum displacement & $\pm 7.6 \mathrm{~cm}$ \\
Maximum load & $7.5 \mathrm{~kg}$ \\
Maximum mass & $27.2 \mathrm{~kg}$ \\
Maximum acceleration & $24.5 \mathrm{~m} / \mathrm{s}^{2}$ \\
Maximum frequency & $15.0 \mathrm{~Hz}$ \\
\hline
\end{tabular}

springs. In all situations was used the same instrumentation. The external force (impact hammer) focused on the second floor of the structure, along with the capture of the output signal (accelerometer) because they present less interference in the signals generated. Figure 7(b) shows the sequence of the experimental procedure.

2.3.3. Forced Vibration Setup. For the experimental tests of forced vibration, an electromechanical machine Quanser $^{\circledR}$ Shake Table II was used. Table 3 shows the main characteristics.

The shake table is managed by a computer and its QUARC $^{\circledR}$ control software or the Matlab interface from Simulink ${ }^{\circledast}$. The input and output signals of the structure were captured by the LVDT (Linear Variable Differential Transformer) type (WI/10 mm T) and (WA/20 mm L), both from the $H B M^{\circledR}$ manufacturer and registered by the Quantum $X^{\circledast}$ data acquisition system. The signal acquisition software is the CatmanEasy ${ }^{\circledR}$, and data were processed on the Matlab software. Figure 8 shows the setup and instrumentation used in the experiments.

For the dynamic tests of the structure under forced vibration, behavior of the structure when subjected to harmonic excitation forces (sinusoidal function), using a peak input amplitude of $0.6 \mathrm{~mm}$ was studied.

Based on the choice of motion imposed on the system, it is possible to determine the FRF from the displacement measurements for each floor, extracting from these curves essential values in the analysis, such as the natural 


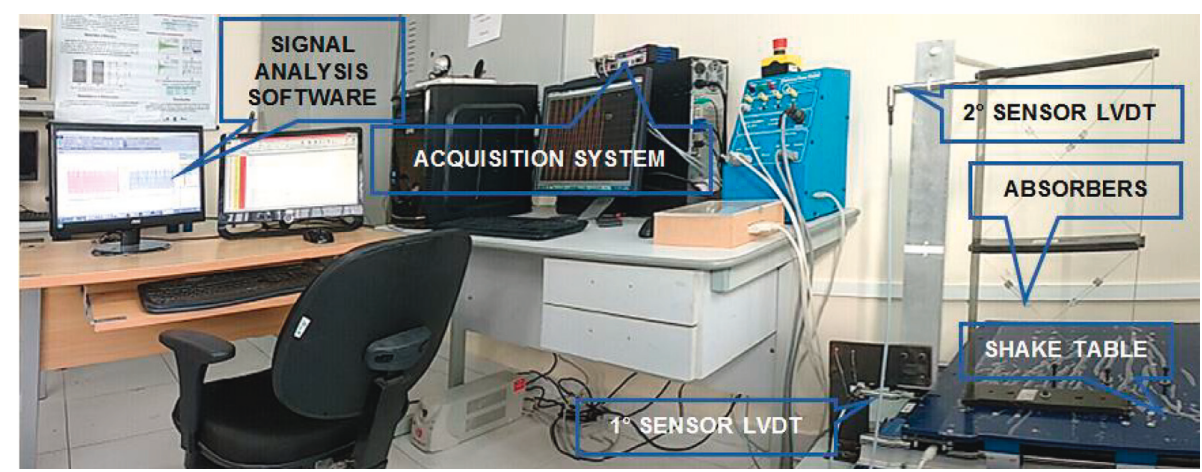

Figure 8: Experimental setup of the system under forced vibration.

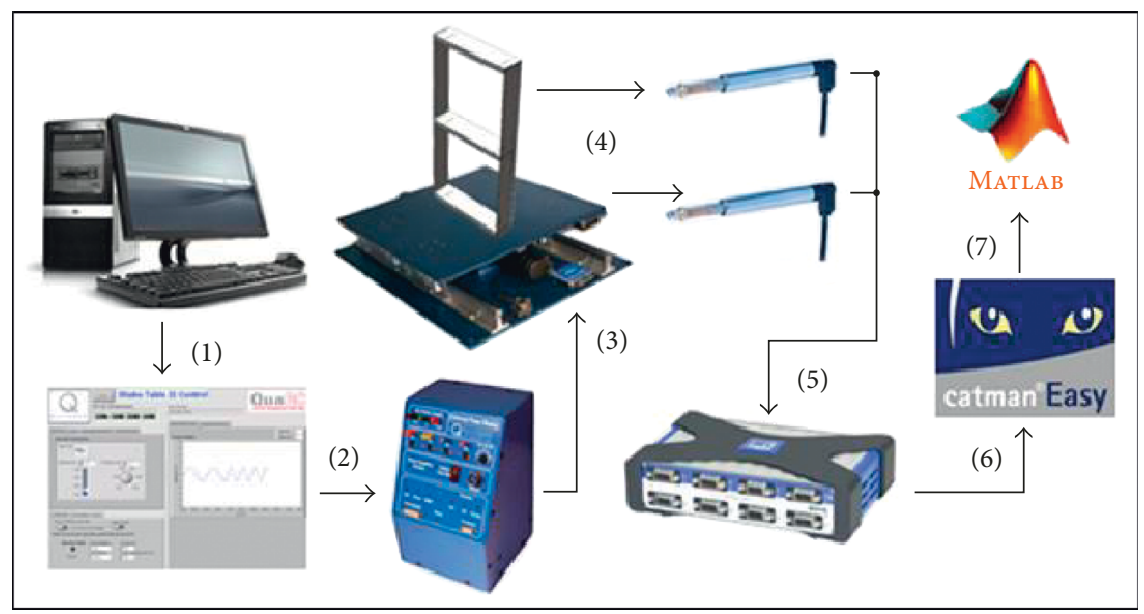

FIGURE 9: Representation of the experimental procedure under forced vibration.

frequencies, the transmissibility of the displacement, and the damping factors. Figure 9 shows the experimental sequence.

There are three stages for the dynamic test of the forced vibration structure: no absorber elements, with the steel springs, and with the SMA-SE coil springs, each subdivided in two measurements concerning the two floors of the structure. The measurements were carried out separately to avoid interference with the reading sensors, due to the small increase in the damping imposed by the friction between the moving parts of the sensor, perceived in previous tests.

All tests followed the same measurement setup and frequency range $(1.0$ to $11 \mathrm{~Hz}$ ), by increments of the $0.05 \mathrm{~Hz}$. For signal pickup, at each frequency was applied a hold time of 10 seconds for the system to stabilize. The signal pickup was performed at a rate of $50 \mathrm{~Hz}$ and a time period of $10 \mathrm{~s}$, totaling 500 resolution points at each measurement. Therefore, each curve was generated with 201 pts, obtaining a good accuracy in the resonance peaks and increasing the precision of the damping values.

Initially, we cut off the offset value and calculated the FFT (Fast Fourier Transformer) for each of these signals and then obtained maximum peak-value. From these maximum peak data points, the FRF was constructed by dividing the output by the input values $[X(w) / Y(w)]$, with a resolution of 201 points, as previously described.

\section{Results and Discussion}

3.1. SMA-SE Coil Springs Characterization. Figure 10(a) shows the result from DSC of the M7 SMA-SE coil spring and the results from the Instron equipment for both M7 and M12 SMA-SE coil springs. The final temperature of austenite transformation $\left(15.7^{\circ} \mathrm{C}\right)$ to the $\mathrm{M} 7$ coil spring is below room temperature, to confirm the superelastic behavior. This behavior was not verified to the M12 coil spring. Figure 10(b) illustrates the force versus displacement curves up to $445 \%$ of strain. For the M7 coil spring, the energy dissipated was $0.015 \mathrm{~J}$ and $0.026 \mathrm{~J}$ for M12 coil spring.

3.2. Predicted Results. For determination of the natural frequencies and modal shapes of the structure subjected to forced vibration, we used (7) and (8) and the experimental data of mass, damping, and stiffness. Figure 11 shows the analytical FRF curves of the system without the incorporation of absorbers, for the first and second floors, obtained from the transfer functions modeled by the Laplace transform theory described in Section 2.1. Table 4 displays the natural frequencies of the structure without absorbers.

Figure 12 shows the results of the numerical simulation (FEM) for the modal shapes of the structure without the incorporation of the absorber elements. It was verified that 


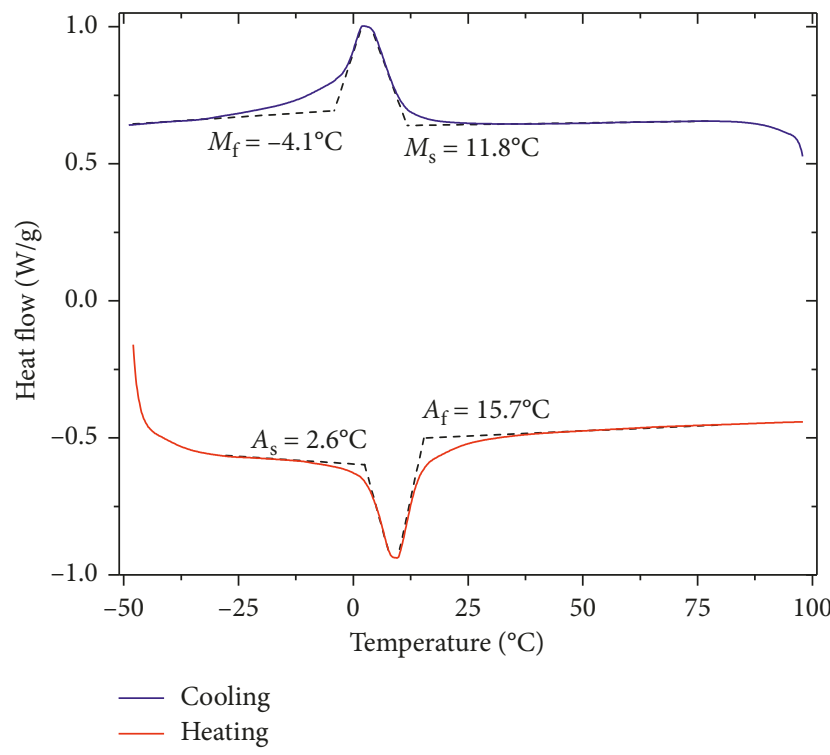

(a)

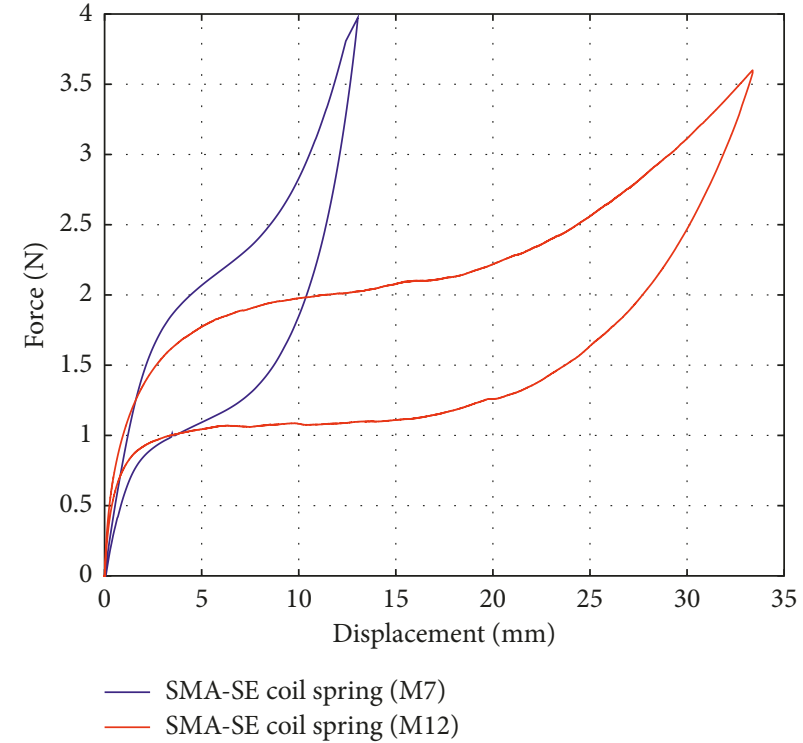

(b)

FIGURE 10: Characterization of SMA-SE absorbers elements. (a) DSC and (b) dynamical test at room temperature and quasistatic load.

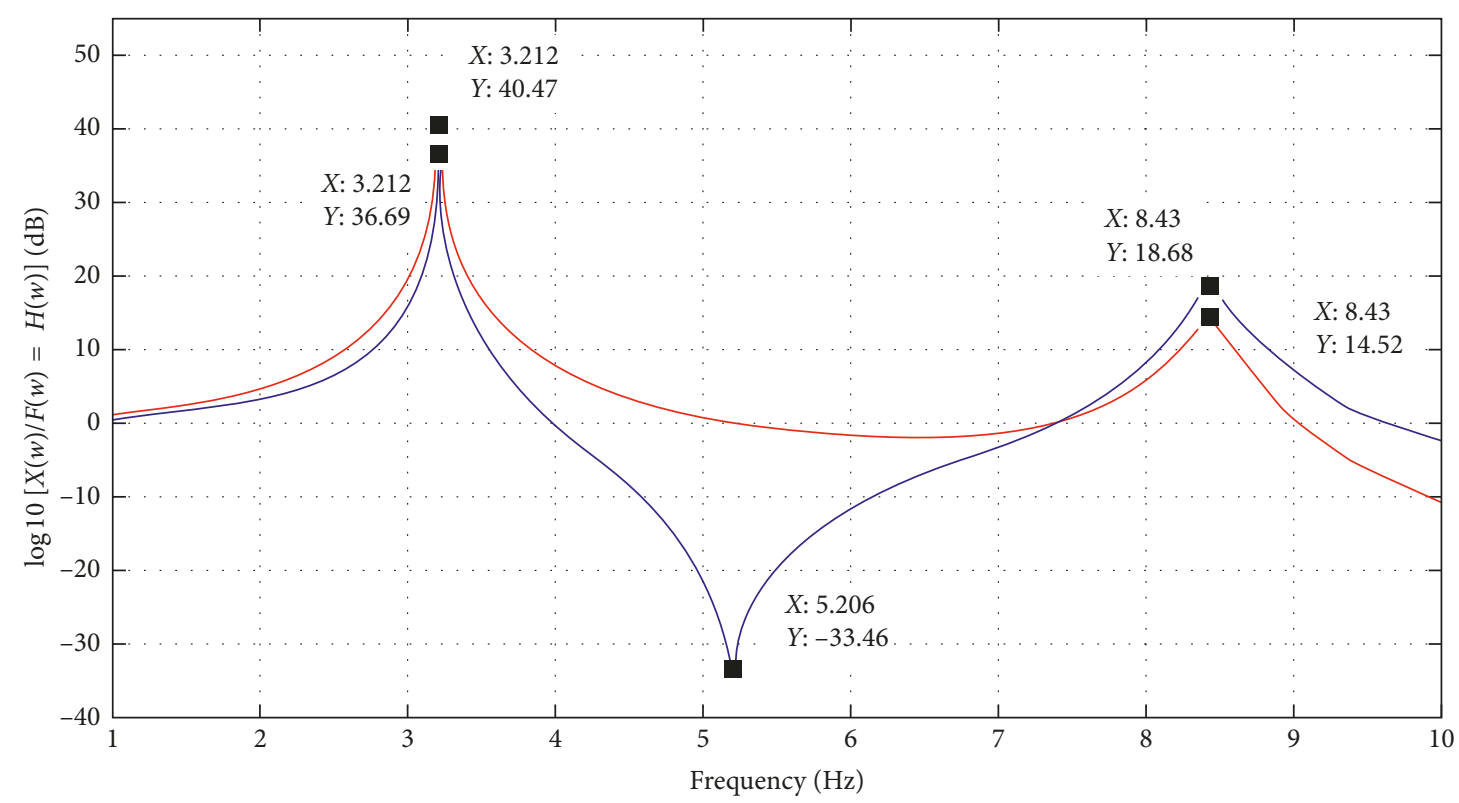

FRF first floor

FRF second floor

FIgURE 11: FRF analytical obtained by the system transfer functions.

TABLE 4: Natural frequencies of the structure without absorbers (free vibration).

\begin{tabular}{|c|c|c|c|c|}
\hline $\begin{array}{l}\text { Natural } \\
\text { frequencies }\end{array}$ & $\begin{array}{l}\text { A: analytical method } \\
(\mathrm{Hz})\end{array}$ & $\begin{array}{l}\text { B: numerical method } \\
(\mathrm{Hz})\end{array}$ & $\begin{array}{c}\text { C: experimental free vibration } \\
(\mathrm{Hz})\end{array}$ & Relative error $(\%)[(A-C) / A] \times 100$ \\
\hline 1st & 3.21 & 3.32 & 3.08 & 4.0 \\
\hline 2nd & 8.43 & 8.73 & 8.25 & 2.1 \\
\hline
\end{tabular}




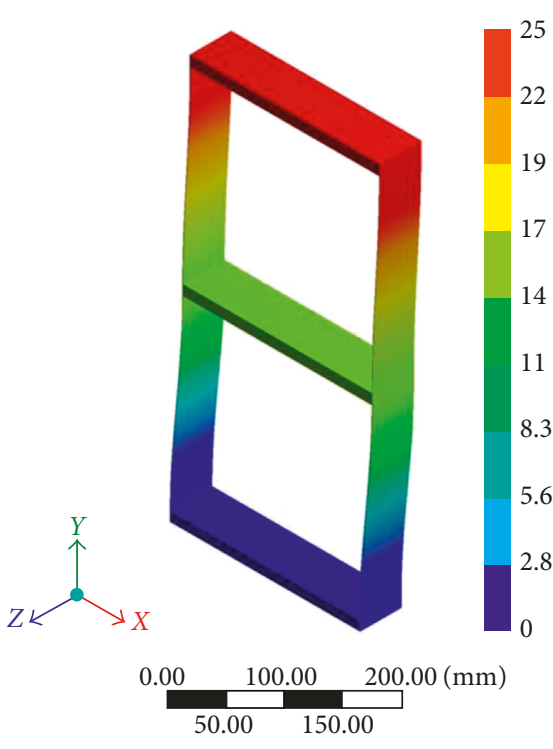

(a)

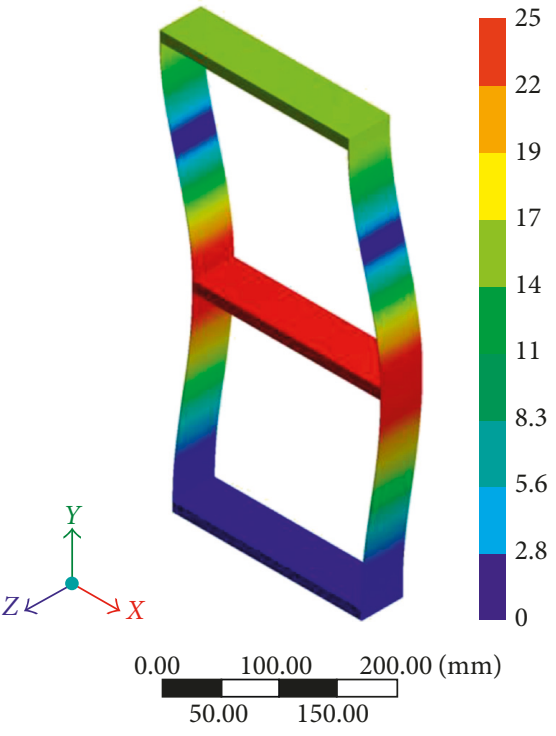

(b)

Figure 12: Modal shape obtained by numerical simulation. (a) First mode and (b) second mode.

the convergence analysis for the mesh size adopted validates the simulation. The modal shapes related to the two main frequencies in side view and their respective minimum and maximum displacement amplitudes are shown in the color bar. It is possible to notice the displacement imposed to the system, observing the position variations of the structure at rest when compared to the same one deformed, in its modal shapes of vibration.

According to the predicted results (Figure 11), we notice that they are in agreement with the numerical results (Figure 12) regarding natural frequencies, with errors from up the $3 \%$. For the modal shapes, in the analytical response curve (Figure 11), it was observed that the highest transmissibility of displacements occurs on the second floor and the first mode. This fact was also observed in the numerical simulation (Figure 12(a)).

In the second modal shape, the analytical response curve (Figure 11) shows the greatest amplitude of displacement in the first floor of the structure; the same behavior was also obtained for the numerical simulation (Figure 12(b)), in which the largest displacements also occur on the first floor.

\subsection{Experimental Results}

3.3.1. Free Vibration. For validation of the predicted results, the transient responses of the structure in the free vibration tests (system acceleration responses) and their respective frequency spectrum FFT were obtained. Figure 13 presents the experimental results for the structure without absorbers and with the incorporation of two configurations, steel springs, and SMA-SE coil springs.

Note that a spring element made of steel stores elastic potential energy and returns a portion to the system in the form of kinetic energy. The difference between the stored energy and the energy recovered is due to the structural damping of the spring itself. However, the damping factor for the steel alloys is tiny and varying between 0.001 and 0.008 [32], so that the mechanical energy dissipation of these elements becomes insufficient to reduce the amplitudes of response. On the other hand, SMA-SE materials have a damping factor about 100 times higher than the steel, on the order of 0.1 to 0.2 , and are known as Hidamets (High Dampers Materials). Therefore, when applying springs manufactured in SMA-SE, the system response suffers a reduction in amplitude [33].

From Figure 13, we can see that the mean peak amplitude achieved for all studied cases was approximately 0.45 $\mathrm{g}$ where "g" represents the gravity acceleration. The response in the time domain for the system without absorbers is very close to that obtained with the incorporation of steel springs (with stiffness similar to that for SMA-SE springs). This behavior confirms that elements of this type of material do not dissipate mechanical energy enough. In opposite, for the SMA-SE spring setup, greater energy dissipation is observed when compared to the previous cases.

Figure 14 illustrates the curves FRF of the system. This function was achieved by dividing the acceleration output signal and the force input signal from a predefined function in the dynamic signal analyzer. The response amplitude peaks are denoted by the behavior described in Figure 13. In this figure, we can see larger amplitudes for the system without the presence of actuators or with the incorporation of steel springs, and a considerable and significant reduction thereof in the SMA-SE coil springs configuration.

Table 4 shows the natural frequency values of the three methods of analysis adopted in this work. When the experimental results of the system in free vibration are compared with the analytical method, for the structure without absorbers, a variation of $4.0 \%$ is observed for the 

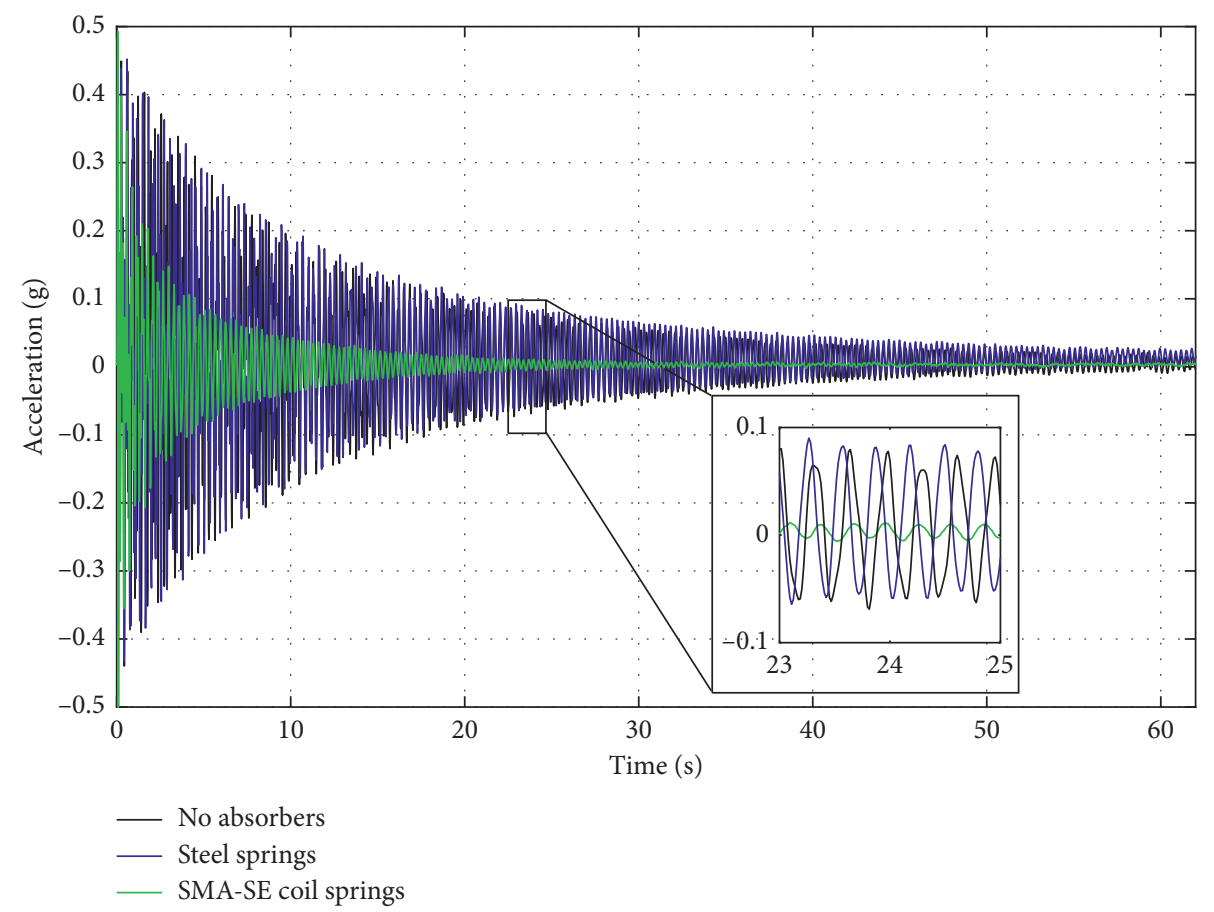

FIGURE 13: Time response for structure subjected to an impact in all configurations.

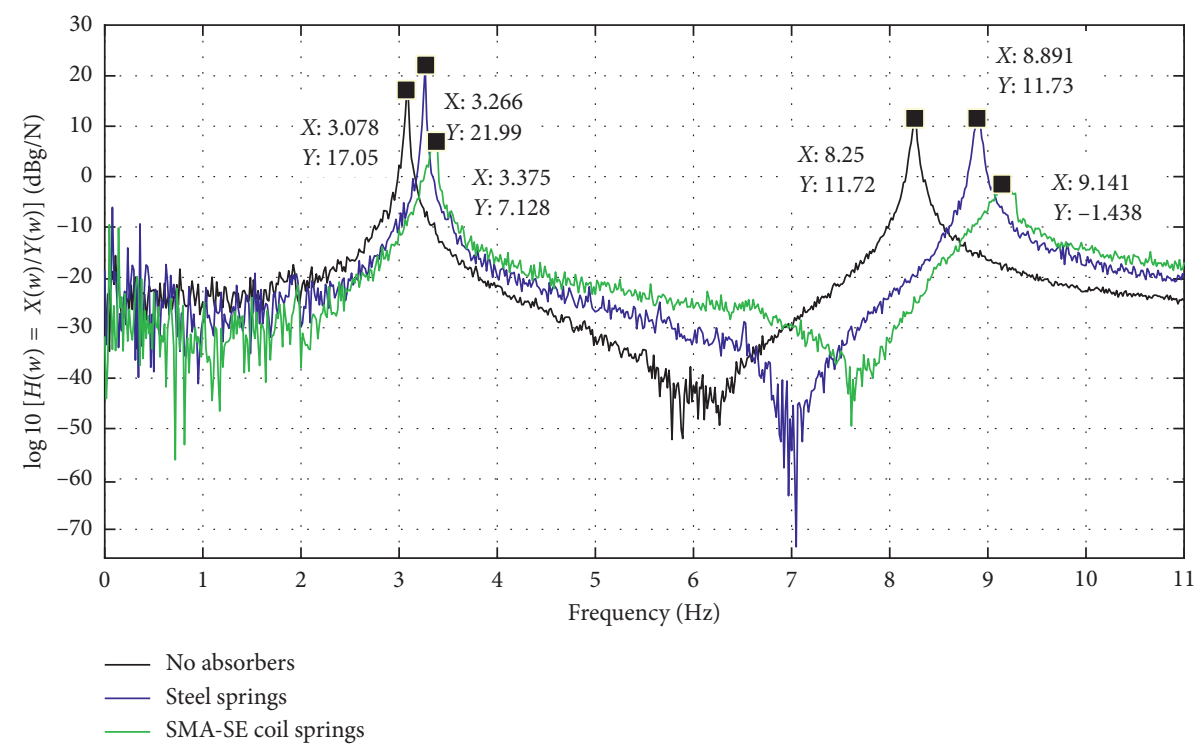

FIgURE 14: Experimental FRF of the system for the configurations adopted in this study.

TABLE 5: Natural frequencies and percentage reduction of amplitudes in free vibration tests.

\begin{tabular}{lcccccc}
\hline Configurations & $\omega_{n 1}(\mathrm{~Hz})$ & $H(w)(\mathrm{g} / \mathrm{N})$ & $\% R[(B-C) / B] \times 100$ & $\omega_{n 2}(\mathrm{~Hz})$ & $H(w)(\mathrm{g} / \mathrm{N})$ & $\% R[(B-C) / B] \times 100$ \\
\hline A: no absorbers & 3.08 & 7.12 & - & 8.25 & 3.85 & - \\
B: steel springs & 3.26 & 12.58 & - & 8.89 & 3.86 & - \\
C: SMA-SE coil springs & 3.37 & 2.27 & 82 & 9.15 & 0.83 & 78 \\
\hline
\end{tabular}

first natural frequency and of $2.1 \%$ for the second natural frequency.

The reason for this variation can be motivated by the consideration of perfect crimping adopted in the method, a fact that not is verified in the real experimental tests. The bolts make the connection between the floors and the columns, which decreases the stiffness of the model. This fact provokes a decrease in the natural frequencies of the system. 


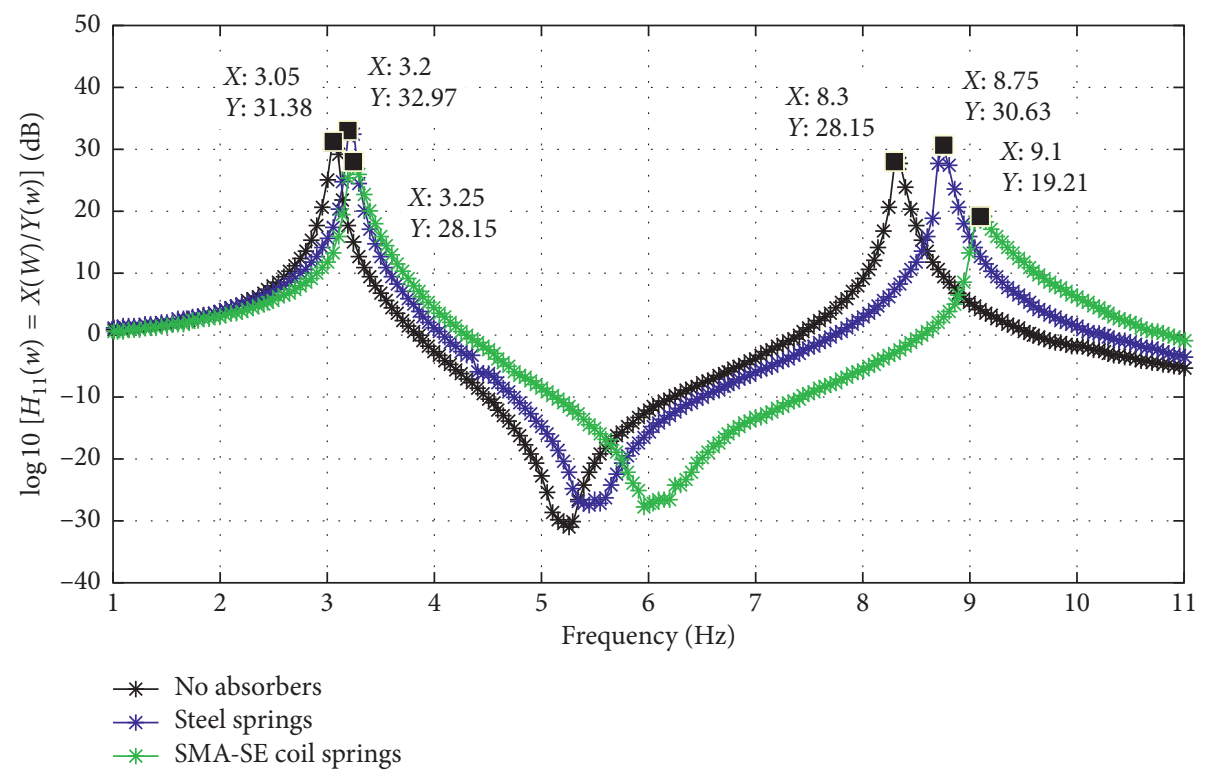

FIGURE 15: Experimental FRF of the first floor of the system.

Table 5 shows the values of the linear acceleration amplitudes. The small variation of natural frequencies of the system in comparison with the structure with steel springs and SMA-SE coil springs is observed. As already expected, an increase in global stiffness causes an increase in the natural frequency. The results of percentage reduction $(\% R)$ of acceleration amplitudes confirm the efficiency of the superelastic coil springs in the control of vibrations. In this configuration, reductions of $82 \%$ for the first natural frequency and $78 \%$ for the second when compared with the structure of steel springs were verified.

If we compare structural damping of the system without absorbers $(\xi=0.0026)$, with the system with steel springs $(\xi=0.0022)$, in both cases, damping factors of the same order of magnitude are observed, which are typical of conventional steel structures.

Concerning the values of attenuation of the of the acceleration signal in time, was verified that when the amplitudes reached a value of $0.03 \mathrm{~g}$, a significant reduction of $72 \%$ for the case of the structure with SMA-SE springs compared to the system with steel springs.

The result of adding a steel spring in parallel is one increase in global stiffness. Just see (7) and (8); if " $k$ " increases, the response amplitude increases too. So, add a steel spring without structural damping, and the response amplitude will increase. Also, the inclusion of a steel spring in a structure may characterize the addition of a secondary system with coupling by mass, and the possibility of a resonance phenomenon occurring and consequently the growth of the response amplitude.

3.3.2. Forced Vibration. For the experimental tests of the system subjected to forced vibration, the method established previously in the experimental methodology was followed, obtaining the curves of frequency response functions, in all configurations. Figure 15 illustrates the FRF obtained for the first floor.

Analyzing the curves in Figure 15, one can observe the same behavior already evidenced in the free vibration tests. For the case of the structure with steel springs, the displacement transmissibility peaks presented higher values for the two modal shapes. This fact indicates that elastic steel elements do not control or minimize vibrations in structures subjected to permanent excitations.

As expected, the FRF of the system with the SMA-SE coil springs presented a significant reduction in the transmissibility peaks, evidencing the high levels of mechanical energy dissipation. The behavior described here can also be visualized in an analogous way for the second floor of the structure, as evidenced in Figure 16.

Table 6 presents the values of natural frequencies and displacement transmissibility relation of the system, obtained from linear FRF. For the system with the SMA-SE coil springs, reductions in the transmissibility peaks " $T_{d}$ " up to $51 \%$ in the first modal shape and up to $73 \%$ for the second shape were obtained.

Regarding the damping factor $(\xi)$, the behavior of the system follows the same pattern perceived in previous analyzes. Table 7 highlights these rates for all modal shapes and their two floors. It seen that the system incorporated with steel springs does not add damping to the structure, presenting mostly values even lower than the structure without absorber. In the case of the system with the SMA-SE coil springs, there is a significant increase in the damping. There is an increase of up to $59 \%$ or approximately 1.6 times in the first modal shape and up to $119 \%$ or 2.2 times for the second mode.

\section{Conclusions}

This paper focuses on the passive control of vibrations using different configurations on the structural system: steel 


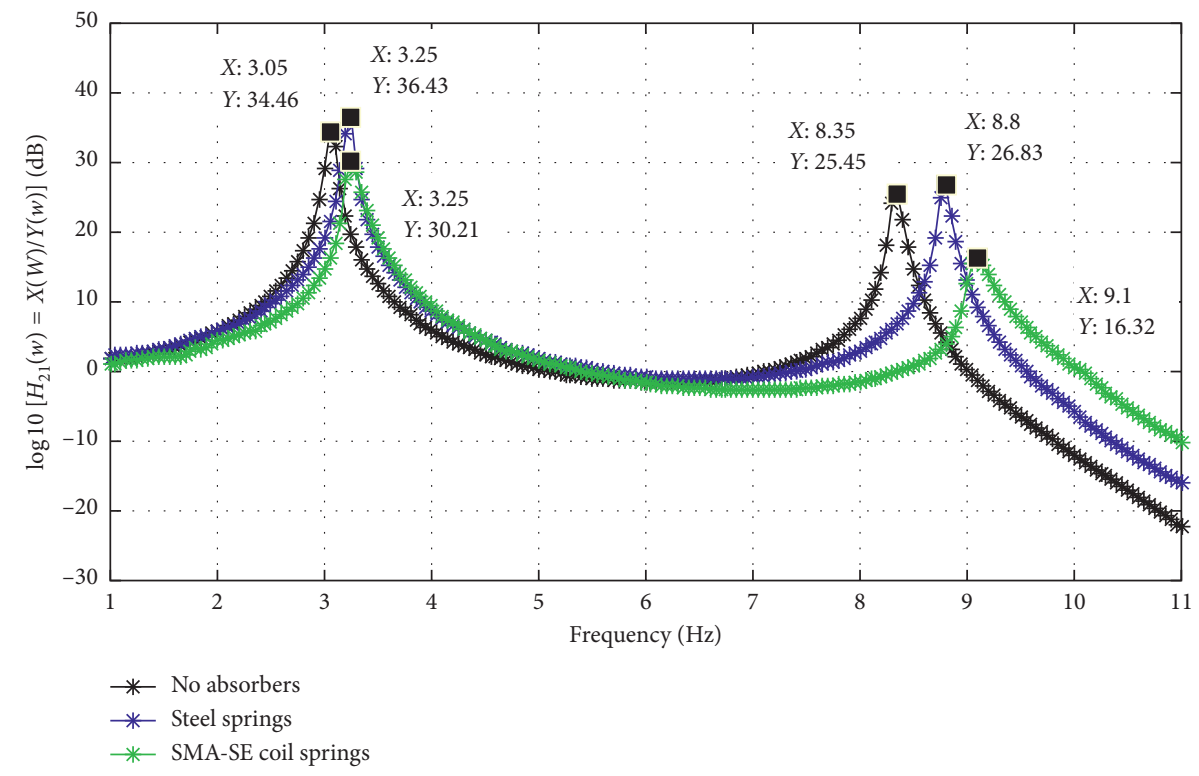

FIGURE 16: Experimental FRF of the second floor of the system.

TABLE 6: Natural frequencies and displacement transmissibility in forced vibration, linear scale.

\begin{tabular}{|c|c|c|c|c|c|c|c|c|c|c|c|c|}
\hline \multirow{3}{*}{ Configurations } & \multicolumn{6}{|c|}{ First floor } & \multicolumn{6}{|c|}{ Second floor } \\
\hline & \multirow{2}{*}{$\omega_{n 1} \mathrm{~Hz}$} & \multicolumn{2}{|c|}{$H(w)_{1}$} & \multirow{2}{*}{$\omega_{n 2} \mathrm{~Hz}$} & \multicolumn{2}{|c|}{$H(w)_{2}$} & \multirow{2}{*}{$\omega_{n 1} \mathrm{~Hz}$} & \multicolumn{2}{|c|}{$H(w)_{1}$} & \multirow{2}{*}{$\omega_{n 2} \mathrm{~Hz}$} & \multicolumn{2}{|c|}{$H(w)_{2}$} \\
\hline & & $T_{d}$ & $\% R^{*}$ & & $T_{d}$ & $\% R^{*}$ & & $T_{d}$ & $\% R^{*}$ & & $T_{d}$ & $\% R^{*}$ \\
\hline A: no absorbers & 3.0 & 37.1 & - & 8.3 & 26 & - & 3.0 & 52.8 & - & 8.3 & 19 & - \\
\hline B: steel springs & 3.2 & 44.5 & - & 8.7 & 34 & - & 3.2 & 66.3 & - & 8.7 & 22 & - \\
\hline C: SMA-SE coil springs & 3.2 & 25.5 & 43 & 9.1 & 9.1 & 73 & 3.2 & 32.4 & 51 & 9.1 & 6.5 & 70 \\
\hline
\end{tabular}

$\% R^{*}=[(B-C) / B] \times 100$.

TABle 7: Structural damping of the system in forced vibration, linear scale.

\begin{tabular}{|c|c|c|c|c|c|c|c|c|}
\hline \multirow{3}{*}{ Configurations } & \multicolumn{4}{|c|}{ First floor } & \multicolumn{4}{|c|}{ Second floor } \\
\hline & \multicolumn{2}{|c|}{$\omega_{n 1}(\mathrm{~Hz})$} & \multicolumn{2}{|c|}{$\omega_{n 2}(\mathrm{~Hz})$} & \multicolumn{2}{|c|}{$\omega_{n 1}(\mathrm{~Hz})$} & \multicolumn{2}{|c|}{$\omega_{n_{2}}(\mathrm{~Hz})$} \\
\hline & $\xi_{1}$ & $\% \widehat{A}^{*}$ & $\xi_{2}$ & $\% \widehat{A}^{*}$ & $\xi_{1}$ & $\% \widehat{A}^{*}$ & $\xi_{2}$ & $\% \widehat{A}^{*}$ \\
\hline A: no absorbers & 0.0133 & - & 0.0067 & - & 0.0144 & - & 0.0065 & - \\
\hline B: steel springs & 0.0142 & - & 0.0053 & - & 0.0123 & - & 0.0055 & - \\
\hline C: SMA-SE coil springs & 0.0172 & 21 & 0.0116 & 119 & 0.0195 & 59 & 0.0115 & 109 \\
\hline
\end{tabular}

$\% \widehat{A}^{*}=[(C-B) / B] \times 100$.

springs and SMA-SE coil springs (NiTi Alloys). The results obtained by different methods (analytical, numerical, and experimental) were representative to compare the modal shapes. The proposed models were obtained in a simplified form and without absorber elements: however, the result confirms that the formulations represent the system as well. In the numerical analysis, good results were obtained using the Ansys in comparison with the analytical results, despite the limitation by the nonconsideration of the friction and the contact between the parts of the structure. A small relative variation up to $3.5 \%$ was obtained for the modal shapes, validating the modeling.

In an experimental modal analysis for the system in free vibration was verified the efficiency of the configurations that adopted the superelastic springs as a vibration absorber element, obtaining significant reductions in the acceleration amplitudes, up to $82 \%$ for the SMA-SE coil springs configuration. Regarding the signal attenuation time, it observed that, for the structure subjected to a lateral impulse (impact hammer), the reductions were considerable. There was a reduction up to $72 \%$ in the SMA-SE coil spring configuration compared to the steel springs.

When analyzed, the system in forced vibration was verified that there was no significant variation in the natural frequencies for the configuration of steel springs when compared with the SMA-SE coil springs. It is perceived a variation of up to $4.6 \%$ for modal shapes. Thus, it is correct to say that amplitude reductions occur due to the increase in structural damping and energy dissipation. Regarding the displacement transmissibility, by analyzing the FRF, it can be 
seen that in comparison with the system with steel springs, the SMA-SE coil springs configuration showed a reduction up to $51 \%$ in the first modal shape and up to $73 \%$ for the second mode.

The damping factors ranging from (0.001 to 0.08) are within the range of expected values for structural damping. If we compare these factors for the SMA-SE spring configuration, there is an increase of up to $59 \%$ in the first modal shape and up to $119 \%$ in the second mode, in comparison with the worst case, the configuration of springs of steel. Thus, we stated that the objectives of the work were satisfactorily achieved, validating the use of SMA-SE in the passive control of vibrations in structures subjected to dynamic excitations.

\section{Data Availability}

The (analytical, numerical, and experimental) data used to support the findings of this study are available from the corresponding author upon request.

\section{Conflicts of Interest}

The authors declare that there are no conflicts of interest regarding the publication of this paper.

\section{Acknowledgments}

The authors thank the Federal University of Campina Grande, LVI (Laboratory of Vibrations and Instrumentation) and the LaMMEA (Multidisciplinary Laboratory of Materials and Structures Active), of the Department of Mechanical Engineering/Federal University of Campina Grande, Brazil, for the field test. This work was supported by the financing granted in the form of scholarship and investment in scientific research fostered by $\mathrm{CNPq}$ (National Council of Research and Development of Brazil) through the projects 306732/2012-2 and 444039/2014-7.

\section{References}

[1] S. S. Rao, Mechanical Vibrations, vol. 4, Pearson Prentice Hall, São Paulo, SP, Brazil, 2008, ISBN 978-85-7605-200-5.

[2] A. K. Chopra, Dynamics of Structures, Vol. 2, Pearson Prentice Hall, Upper Saddle River, NJ, USA, 1995.

[3] L. N. F. France and J. Sotelo Jr., Introduction to Mechanical Vibrations, vol. 1, Edgard Blücher, São Paulo, SP, Brazil, 2006, ISBN 978-85-2120-338-4, in Portuguese.

[4] A. A. Correia, "System vibrations with 1DOF," in Dynamics, Higher Technical Institute, Nicosia, Cyprus, 2007.

[5] M. J. Brennan, "Some recent developments in adaptive tuned vibration absorbers/neutralizers," Shock and Vibration, vol. 13, no. 4-5, pp. 531-543.

[6] J. Liu and K. Liu, "A tunable electromagnetic vibration absorber: characterization and application," Journal of Sound and Vibration, vol. 295, no. 3-5, pp. 708-724, 2006.

[7] P. A. L. Yánez, "Seismic analysis of buildings by continuous environment technique," Ph.D. thesis, Structural Engineering, School of Engineering of São Carlos, Federal University of São Paulo (USP), São Carlos, SP, USA, 1992, in Portuguese.
[8] J. A. V. Veloso, "Man-induced earthquakes," We off the axis, Brasilia, Brazil, July 2016, in Portuguese, http://www.nosrevista. com.br/2012/09/18/terremotos-induzidos-pelo-homem/.

[9] F. L. B. Saavedra, "Comparative study in seismic analysis of building structures," M.S. dissertation, Civil Engineering Sciences, Federal University of Rio de Janeiro (UFRJ), Rio de Janeiro, RJ, Brazil, 1991, in Portuguese.

[10] M. Dolce and D. Cardone, "Mechanical behavior of shape memory alloys for seismic applications: austenite $\mathrm{Ni}-\mathrm{Ti}$ wires subjected to tension," International Journal of Mechanical Sciences, vol. 43, no. 11, pp. 2657-2677, 2001.

[11] M. Dolce, D. Cardone, and R. Marnetto, "SMA re-centering devices for seismic isolation of civil structures," in Proceedings of the SPIE, vol. 4330, pp. 238-249, Chiba, Japan, July 2001.

[12] A. E. V. Lopes, "Seismic risk in Brazil and its impact on great works," Journal of the Institute of Engineering, no. 58, 2010, in Portuguese, https://www.institutodeengenharia.org.br/site/ 2010/05/02/edicao-58/.

[13] A. E. V. Lopes, Seismic Intensities of Earthquakes: Formulation of Seismic Scenarios in Brazil, vol. 91, pp. 90-102, USP Magazine, São Paulo, SP, Brazil, 2011, in Portuguese, 2011.

[14] D. Halliday and R. Resnick, Fundamentals of Physics: Mechanics, vol. 4, LTC, Rio de Janeiro, RJ, USA, 2008, ISBN 978-85-2161605-4, in Portuguese.

[15] E. M. Kervin Jr., "Damping of flexural waves by a constrained viscoelastic layer," Journal of Acoustical Society of America, vol. 31, no. 7, pp. 952-962, 1959.

[16] D. Ross, E. E. Ungar, and E. M. Kervin Jr., "Damping of plate flexural vibrations by means of viscoelastic layer," in Structural Damping, ASME, New York, NY, USA, 1959.

[17] K. Willians, G. Chiu, and R. Bernhard, "Adaptative-passive absorbers using shape memory alloys," Journal of Sound and Vibration, vol. 249, no. 5, pp. 835-848, 2002.

[18] S. B. Choi and J. H. Hwang, "Structural vibrations control using shape memory actuators," Journal of Sound and Vibration, vol. 231, no. 4, pp. 1168-1174, 2000.

[19] P. Mahmoodi, "Structural dampers," Journal of Structural Division, vol. 95, no. 8, pp. 1661-1672, 1969.

[20] L. A. P. Semão, "Use of shape memory alloys in the control of vibrations in intelligent civil engineering structures," M.S. dissertation, Civil Engineering-Structures and Geotechnics, Faculty of Sciences and Technology, Nova de Lisboa University, Lisbon, Portugal, 2010, in Portuguese.

[21] M. Alam, M. Youssef, and M. Nehdi, "Utilizing shape memory alloys to enhance the performance and safety of civil infrastructure: a review," Canadian Journal of Civil Engineering, vol. 34, no. 9, pp. 1075-1086, 2007.

[22] T. W. Duerig, K. N. Melton, D. Stöckel, and C. M. Wayman, Engineering Aspects of Shape Memory Alloys, ButterworthHeinemann Ltd, London, UK, 1990, ISBN 0-750-61009-3.

[23] D. C. Lagoudas, Shape Memory Alloys: Modelling and Engineering Application, D. C. Lagoudas, Ed., Springer, Houston, TX, USA, 2008.

[24] C. Menna, F. Auricchio, and D. Asprone, "Applications of SMA in structural engineering," in Shape Memory Alloy Engineering, Butterworth-einemann Limited, Oxford, UK, 2015, ISBN 978-0-08-099920-3.

[25] F. Auricchio, R. L. Taylor, and J. Lubliner, "Shape-memory alloy: macro modelling and numerical simulations of the superelastic behavior," Computer Methods Applied Mechanics Engineering, vol. 146, no. 3-4, pp. 281-312, 1997.

[26] J. Wilson and M. Wesolowsky, "Shape memory alloys for seismic response modification: a state-of-the-art review," Earthquake Spectra, vol. 21, no. 2, pp. 569-601, 2005. 
[27] L. Lecce and A. Concilio, Shape Memory Alloy Engineering: For Aerospace, Structural and Biomedical Applications, Butterworth-Heinemann, Oxford, UK, 2015, ISBN: 978-0-08099920-3.

[28] L. Delaey, R. V. Krishnan, and H. Tas, "Thermoelasticity, pseudoelasticity, and the memory effects associated with martensitie transforations: structural and microestructural changes associated with the transformations," Journal of Materials Science, vol. 9, no. 9, pp. 1521-1535, 1974.

[29] L. Delaey, R. V. Krishnan, and H. Tas, "Thermoelasticity, pseudoelasticity, and the memory effects associated with martensitie transforations: the macroscopic mechanical behavior," Journal of Materials Science, vol. 9, no. 9, pp. 15361544, 1974.

[30] K. Tanaka, S. Kobayashi, and Y. Sato, "Thermo-mechanics of transformation pseudo-elasticity and shape memory effect in alloys," International Journal of Plasticity, vol. 2, no. 1, pp. 59-72, 1986.

[31] Y. J. O. Moraes, "Dynamical analysis applied to control passive of vibrations in a structural device incorporating superelastic NiTi mini coils springs," M.S. thesis, Mechanical Engineering, Federal University of Campina Grande, Campina Grande, PB, Brazil, 2017, in Portuguese.

[32] C. E. Beards, Structural Vibration: Analysis and Damping, Halsted Press, New York, NY, USA, 1996.

[33] S.-H. Chang and S.-K. Wu, "Damping characteristics of SMA on their inherent and intrinsic internal friction," in Handbook of Mechanics of Materials, C.-H. Hsueh, S. Schmauder, C.-S. Chen et al., Eds., Springer Nature Singapore Pvt. Ltd., Singapore, 2018. 


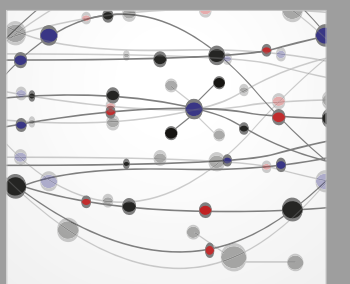

The Scientific World Journal
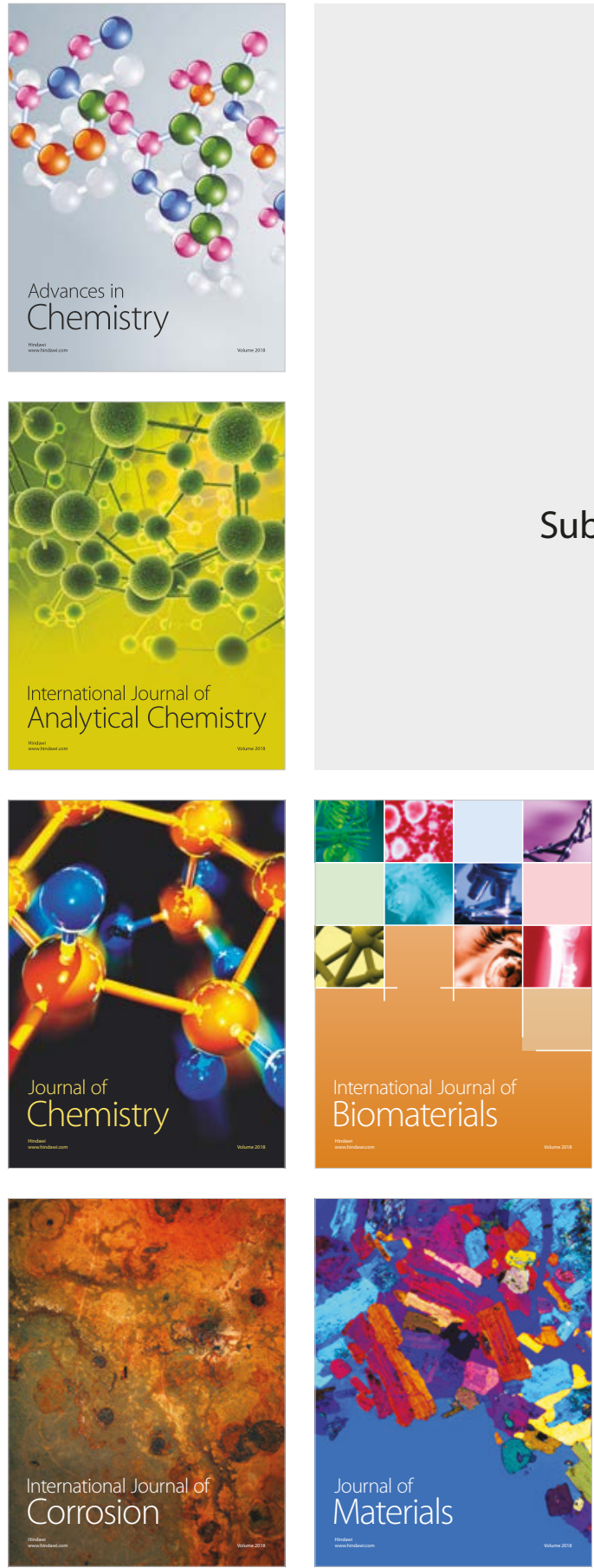

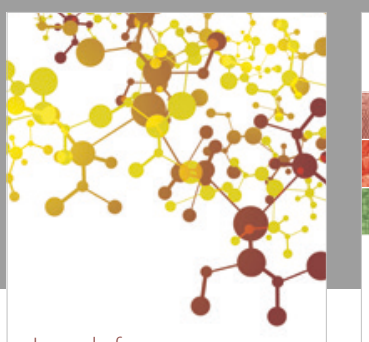

Journal of

Applied Chemistry
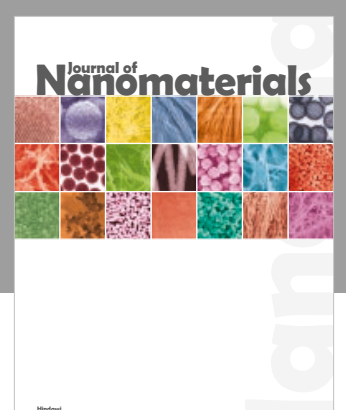

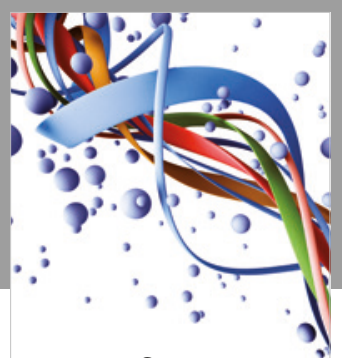

Scientifica

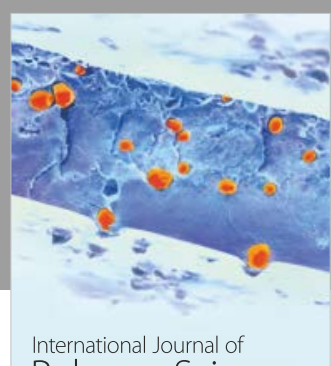

Polymer Science

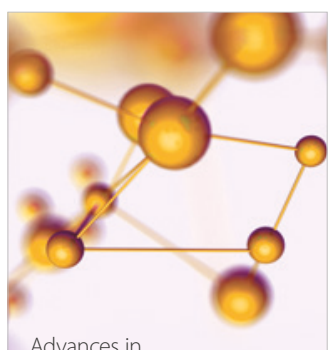

Physical Chemistry
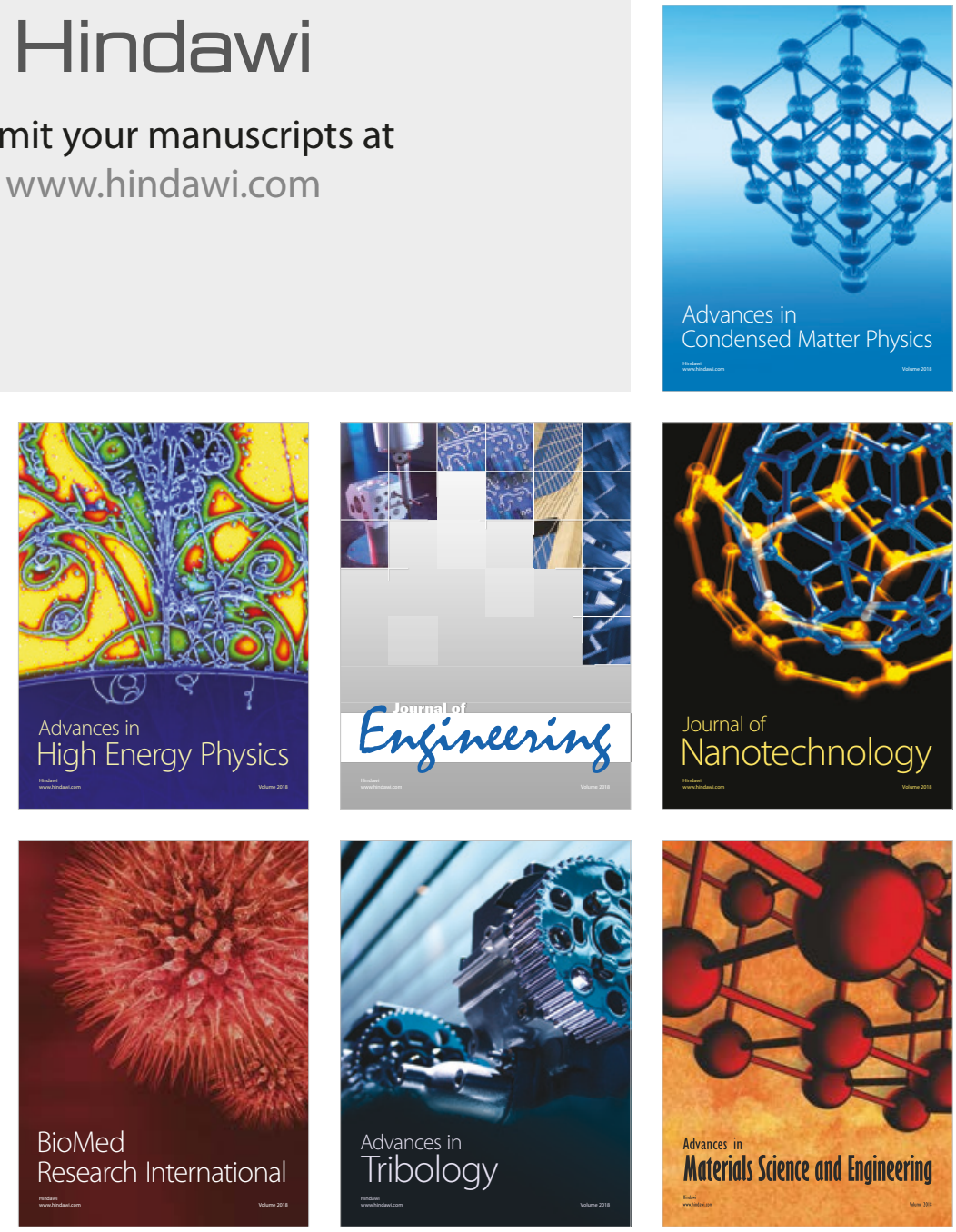